Quim. Nova, Vol. 36, No. 6, 880-884, 2013

\title{
DETERMINAÇÃO ESPECTROFOTOMÉTRICA DE SULFATO EM ÁLCOOL ETÍLICO COMBUSTÍVEL EMPREGANDO DIBROMOSULFONAZO III
}

\author{
Jorge S. Almeida, Vitória R. B. Soares, Camila J. Andrade, José Domingos S. da Silva, Alaílson F. Dantas, Gisele O. da \\ Rocha e Leonardo S. G. Teixeira* \\ Instituto de Química, Universidade Federal da Bahia, Campus de Ondina, 40170-115 Salvador - BA, Brasil
}

Recebido em 23/8/12; aceito em 20/12/12; publicado na web em 15/4/13

\begin{abstract}
SPECTROPHOTOMETRIC DETERMINATION OF SULPHATE IN ETHANOL FUEL USING DIBROMOSULPHONAZO III. A sensitive spectrophotometric method was developed for sulphate determination in automotive ethanol fuel. The method based on the reaction of the analyte with barium-dibromosulphonazo(III) complex lead to a decrease in the magnitude of the absorbance signals monitored at $649 \mathrm{~nm}$. No sample pretreatment is required and the proposed method allows sulphate determination in the $0.45-6.50 \mathrm{mg} \mathrm{L}^{-1}$ range with R.S.D. $<2 \%$ and limit of detection of $0.14 \mathrm{mg} \mathrm{L}^{-1}$. The method has been successfully applied for sulphate determination in automotive ethanol fuel and the results agreed with the reference chromatographic method.
\end{abstract}

Keywords: sulphate; ethanol fuel; spectrophotometry.

\section{INTRODUÇÃO}

As crescentes preocupações ambientais e os constantes aumentos dos preços do petróleo e seus derivados têm elevado o interesse de muitos países na utilização de combustíveis alternativos de fontes renováveis. Dentre os combustíveis alternativos aos derivados de petróleo, o álcool etílico combustível (AEC) tem se destacado no Brasil e vem sendo utilizado em misturas com a gasolina automotiva ou em automóveis movidos exclusivamente com esse combustível. ${ }^{1}$

Em 2011, a produção de álcool etílico anidro combustível (AEAC) no Brasil para adição à gasolina foi de 8,0 milhões de $\mathrm{m}^{3}$, enquanto que a produção de álcool etílico hidratado combustível (AEHC) foi de 19,6 milhões de $\mathrm{m}^{3}{ }^{2}{ }^{2} \mathrm{O}$ processo de produção de AEC é realizado pela fermentação da biomassa da cana de açúcar sendo necessário no processo um controle do $\mathrm{pH}$ para impedir a proliferação de micro-organismos no mosto. Muitas vezes, a adequação deste parâmetro é realizada pela adição de ácidos inorgânicos, como o sulfúrico. ${ }^{3} \mathrm{Se}$ por um lado existe a necessidade de um controle rígido do $\mathrm{pH}$ do meio fermentativo, por outro, é importante manter o teor de sulfato em baixas concentrações, com o intuito de evitar a possível corrosão de peças metálicas do motor e/ou desativação dos catalisadores dos automóveis.

Um dos maiores problemas causados pelo uso do AEHC é sua capacidade corrosiva frente a peças metálicas dos motores dos automóveis. ${ }^{4}$ Entre os principais fatores que potencializam a corrosão pelo álcool nos motores estão a acidez livre, que está relacionada com a capacidade de transferência de oxigênio, e a presença de íons como cloreto e sulfato e, ainda, metais que aumentam a força iônica da solução e consequentemente sua condutividade. ${ }^{5}$ Algumas bactérias têm participação direta neste processo de corrosão. Neste caso, o íon sulfato é utilizado por bactérias redutoras onde este íon atua como um receptor de elétrons em vez de um receptor de oxigênio. ${ }^{6}$ No processo de redução há produção de sulfeto em solução e acidificação do meio, causando a precipitação imediata de íons metálicos no álcool na forma de sulfetos metálicos pouco solúveis. O gás sulfídrico formado por essas bactérias é convertido em enxofre elementar, atacando diretamente o ferro que é o principal componente do aço, ocasionando a oxidação do material. ${ }^{2}$

\footnotetext{
*e-mail: lsgt@ufba.br
}

Para manter maior controle sobre a presença de contaminantes inorgânicos no AEC a determinação de sulfato deve ser efetuada por métodos suficientemente sensíveis para atender ao teor especificado pela legislação brasileira. A Agência Nacional do Petróleo, Gás Natural e Biocombustíveis (ANP) estabelece que a concentração máxima de sulfato no AEC é de $4 \mathrm{mg} \mathrm{kg}^{-1}$, sendo a cromatografia de íons a técnica a ser empregada nesta determinação. ${ }^{7}$ Embora a cromatografia de íons se apresente como uma técnica sensível e seletiva, o procedimento é demorado e caro, exigindo pessoal qualificado para a manipulação de reagentes e equipamentos. ${ }^{4}$ Dessa forma, é possível encontrar na literatura métodos alternativos para determinação de sulfato em AEC empregando a eletroforese capilar, ${ }^{8}$ condutometria, ${ }^{2}$ fluorescência de raios- $\mathrm{X}^{4}$ e, especialmente, a espectrofotometria UV-Vis ${ }^{3,9}$ devido à simplicidade, rapidez, fácil implementação e disponibilidade instrumental nos laboratórios. ${ }^{10,11}$ Nesse sentido, reagentes da família do sulfonazo, a exemplo do dimetilsulfonazo III, vêm sendo empregados em métodos espectrofotométricos devido a capacidade de formação de complexos com diversas espécies em diferentes faixas de $\mathrm{pH}$, possibilitando estratégias para determinação direta de íons metálicos e indireta de ânions. , $^{3,12}$

No presente trabalho, apresenta-se um método espectrofotométrico alternativo para determinação indireta de sulfato em amostras de AEC empregando o reagente da família dos sulfonazos 3,6-di(p-bromo-o-sulfofenilazo)-4,5 dihidroxi-2,7 naftaleno dissulfônico, simplificadamente chamado de dibromosulfonazo III ou DBSA III. No procedimento, o decréscimo dos sinais de absorvância do complexo $\mathrm{Ba}^{2+}$-DBSA III devido à presença de íons sulfatos nas amostras é monitorado em $649 \mathrm{~nm}$.

\section{PARTE EXPERIMENTAL}

\section{Reagentes e soluções}

Todas as soluções foram preparadas a partir de reagentes de grau de pureza analítica e água deionizada ultrapura, com resistividade $18 \mathrm{M} \Omega \mathrm{cm}^{-1}$, oriunda de um sistema de purificação Milli-Q ${ }^{\circledR}$ (Millipore, Bedford, EUA). As vidrarias e frascos utilizados foram previamente colocados em banho ácido contendo solução de $\mathrm{HNO}_{3}$ $10 \%$ (v/v) por no mínimo 24 h, e, então, lavados com água deionizada antes do uso. 
A solução estoque de sulfato $0,1033 \mathrm{~mol} \mathrm{~L}^{-1}$ foi preparada a partir da dissolução de 1,3956 g de $\mathrm{K}_{2} \mathrm{SO}_{4}$ (Merck, Brasil), previamente seco por $2 \mathrm{~h}$ à $120^{\circ} \mathrm{C}$, em $100,0 \mathrm{~mL}$ de água. A solução estoque de DBSA III (J.T. Baker, México) foi preparada numa concentração de $0,10 \%(\mathrm{~m} / \mathrm{v})\left(1,1814 \times 10^{-3} \mathrm{~mol} \mathrm{~L}^{-1}\right)$ pela dissolução de 0,1000 $\mathrm{g}$ do reagente em $100 \mathrm{~mL}$ de água. Uma solução estoque de íons bário $\left(0,1015 \mathrm{~mol} \mathrm{~L}^{-1}\right)$ foi preparada pela solubilização de 2,6530 $\mathrm{g}$ de $\mathrm{Ba}\left(\mathrm{NO}_{3}\right)_{2}$ (Merck, Brasil) em $100 \mathrm{~mL}$ de água. A solução de Tergitol XD (1-[2-[2-(3-methoxypropoxy)propoxy] ethoxy]butane) $(5 \%, \mathrm{~m} / \mathrm{v})$ foi preparada pela solubilização do tensoativo numa solução tampão de citrato de sódio/ácido cítrico (Merck) 0,05 mol $\mathrm{L}^{-1}$, previamente ajustado para $\mathrm{pH} 2,5$. Foi utilizada solução de EDTA $0,5 \mathrm{~mol} \mathrm{~L}^{-1}$ preparada pela dissolução de 14,61 gramas do sal em 100,0 mL de água.

As soluções dos sais $\left(1000 \mathrm{mg} \mathrm{L}^{-1}\right)$ para a avaliação dos interferentes foram preparadas a partir de reagentes de grau analítico de pureza. Os sais utilizados nos testes de interferência foram: $\mathrm{NaH}_{2} \mathrm{PO}_{4}$ (Merck), $\mathrm{KNO}_{3}$ (Merck), $\mathrm{Mg}\left(\mathrm{NO}_{3}\right)_{2}$ (Fluka), $\mathrm{Ca}\left(\mathrm{NO}_{3}\right)_{2}$ (Fluka), $\mathrm{Cu}\left(\mathrm{NO}_{3}\right)_{2}$ (Quemis), $\mathrm{Fe}\left(\mathrm{NO}_{3}\right)_{3}$ (Quemis).

Para o estudo da acidez, o pH foi variado de 2 a 12 com a adição de soluções tampão aquosas $0,05 \mathrm{~mol} \mathrm{~L}^{-1}$ preparados a partir de citrato de sódio/ácido nítrico ( $\mathrm{pH} 2,0$ a 3,5); acetato de sódio/ácido acético ( $\mathrm{pH} 3,8$ a 5,7); hexamina/ácido clorídrico ( $\mathrm{pH}$ 6,0 a 7,0), tris/ácido clorídrico ( $\mathrm{pH} 7,5$ a 9,0) e borato de sódio/ácido bórico (9,5 a 12).

Para ajuste do teor alcoólico das soluções de referência utilizou-se álcool etílico hidratado P.A. (Merck, min. 95,1\%).

As amostras de AEHC foram coletadas em postos revendedores de combustíveis em Salvador-BA e armazenadas em recipientes PET (âmbar) à $4{ }^{\circ} \mathrm{C}$ até o momento das análises.

\section{Equipamentos}

As medidas de absorvância foram realizadas empregando um espectrofotômetro USB 2000 (Ocean Optics, EUA) equipado com cela de quartzo com $10 \mathrm{~mm}$ de caminho óptico. O software operacional Spectra Suite (Ocean Optics) foi utilizado na aquisição dos dados.

Os ajustes de $\mathrm{pH}$ foram realizados empregado um potenciômetro 827 pH LAB (Metrohm, Suíça) acoplado a um eletrodo de vidro combinado com eletrodo de referência de $\mathrm{Ag} / \mathrm{AgCl}\left(\mathrm{KCl} 3,0 \mathrm{~mol} \mathrm{~L}^{-1}\right)$. $\mathrm{O}$ pHmetro foi calibrado com tampões aquosos.

As determinações cromatográficas foram realizadas em cromatógrafo de íons com duplo canal e detector de condutividade Dionex (São Paulo, Brasil) modelo ICS-1100 com injetor automático modelo AS-DV 40, e sistema de regeneração eluente (ASRS $2 \mathrm{~mm}$ com corrente 68 $\mathrm{mA}$ ). As colunas utilizadas neste sistema foram a ÍonPac AS11-HC 2 $\times 250 \mathrm{~mm}$ e a IonPac AG11-HC guard column $2 \times 50 \mathrm{~mm}$ (Dionex).

\section{Procedimento}

Para as determinações espectrofotométricas, transferiu-se para um balão volumétrico de $10 \mathrm{~mL}$ uma alíquota de $650 \mu \mathrm{L}$ de uma solução $1,015 \times 10^{-3} \mathrm{~mol} \mathrm{~L}^{-1}$ de $\mathrm{Ba}\left(\mathrm{NO}_{3}\right)_{2}, 5 \mathrm{~mL}$ de etanol hidratado P.A., 800 $\mu \mathrm{L}$ da solução de DBSA III $0,10 \%(\mathrm{~m} / \mathrm{v})$ e alíquotas da solução de

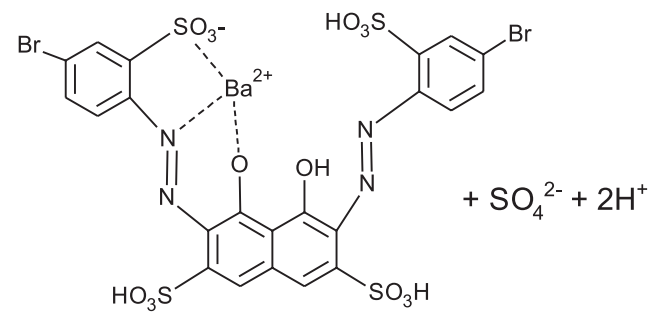

sulfato de modo que a concentração final do analito estivesse na faixa entre 0 a $6,5 \mathrm{mg} \mathrm{L}^{-1}$. Posteriormente completou-se o volume do balão com solução de Tergitol tamponado em $\mathrm{pH}$ 2,5, agitou-se e mediu-se a absorvância do complexo em $649 \mathrm{~nm}$. Utilizou-se um branco do reagente, preparado da mesma forma, no entanto, sem adição de $\mathrm{Ba}\left(\mathrm{NO}_{3}\right)_{2}$ ou sulfato. Para a preparação das soluções para análise das amostras de AEHC substituiu-se a adição do etanol hidratado P.A. por $5 \mathrm{~mL}$ de amostra. Testes de recuperação foram realizados em cinco amostras de AEHC por meio da adição de $2,58 \mathrm{mg} \mathrm{L}^{-1}$ de sulfato nessas amostras, seguida da adição de $\mathrm{Ba}\left(\mathrm{NO}_{3}\right)_{2}$, DBSA III e Tergitol, conforme descrito anteriormente.

Como método comparativo, empregou-se a cromatografia de íons, preconizado pela ANP para determinação de sulfato em amostras de AEC. ${ }^{13}$ Nas determinações, $25 \mu \mathrm{L}$ de cada amostra foram injetados sem diluição com o auxílio de injetor automático. A eluição foi realizada em modo gradiente, empregando-se entre 1 e $65 \mathrm{mmol} \mathrm{L}$ de $\mathrm{KOH}$ a uma vazão de $0,38 \mathrm{~mL} \mathrm{~min}^{-1}$ com tempo total de corrida de $28 \mathrm{~min}$.

\section{RESULTADOS E DISCUSSÃO}

O DBSA III é um reagente da família dos sulfonazos com massa molecular de 846,44 $\mathrm{g} \mathrm{mol}^{-1}$ que possui coloração azul em solução aquosa com máximo de absorção em $579 \mathrm{~nm}$ e, inicialmente, foi empregado como indicador visual em titulações de sulfato. ${ }^{14,15} \mathrm{O}$ princípio químico da reação empregada para determinação espectrofotométrica de sulfato está relacionado com a capacidade de precipitação do analito, presente na solução da amostra, com o bário presente no complexo $\mathrm{Ba}^{2+}$-DBSA III, formado previamente em meio tamponado em $\mathrm{pH}$ 2,5. A presença de $\mathrm{SO}_{4}{ }^{2-}$ provoca o deslocamento dos íons $\mathrm{Ba}^{2+}$ do complexo, deixando em solução o reagente livre na forma DBSA III, conforme reação esquematizada na Figura 1.

Os espectros da solução do reagente, bem como do complexo formado com o bário foram traçados contra um branco de água deionizada. Conforme pode ser observado na Figura 2, em meio ácido, o reagente cromogênico DBSA III possui absorção máxima em 579 nm, enquanto que o complexo $\mathrm{Ba}^{2+}$-DBSA III possui absorção máxima em $649 \mathrm{~nm}$. No presente trabalho, a diminuição da concentração do complexo foi monitorada espectrofotometricamente pelo decréscimo da intensidade dos sinais de absorvância do complexo $\mathrm{Ba}^{2+}$-DBSA III, sendo a resposta analítica inversamente proporcional ao aumento da concentração de $\mathrm{SO}_{4}^{2-}$ presente no meio reacional.

\section{Efeito do pH}

$\mathrm{O}$ controle de $\mathrm{pH}$ nas diversas reações com ligantes da família dos sulfonazos é extremamente importante para adequar a seletividade da complexação com diferentes íons metálicos. ${ }^{16}$ Além disso, a absortividade molar de um determinado complexo pode variar com a mudança de $\mathrm{pH}$ do meio, o que pode acarretar numa variação da sensibilidade de um método analítico. ${ }^{17}$ Sendo assim, é importante se investigar a influência da acidez no sistema.

A avaliação da influência da acidez na formação do complexo

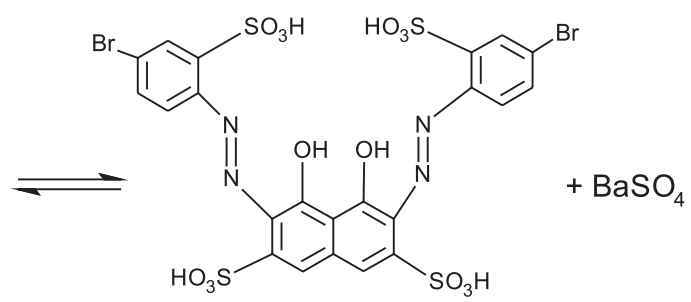

Figura 1. Reação entre o íon sulfato e o complexo $\mathrm{Ba}^{2+}$-DBSA III 


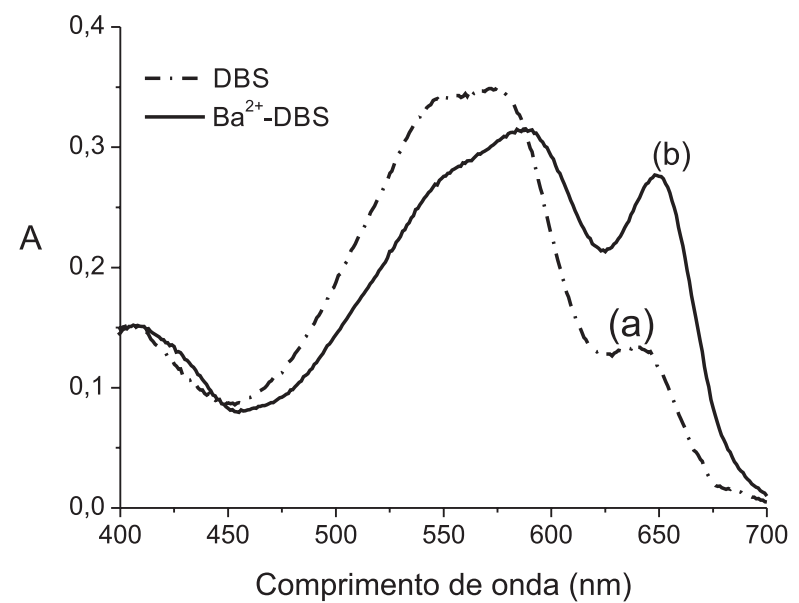

Figura 2. Espectros de absorção: (a) do reagente DBSA III e (b) do complexo $\mathrm{Ba}^{2+}$-DBSA III em $\mathrm{pH} 2,5$

entre bário e DBSA III foi avaliada em pH entre 2 e 12, com a adição das respectivas soluções tampão. Verificou-se que os $\mathrm{pH}$ resultantes das amostras e soluções padrão alcoólicas apresentaram valores próximos aos valores nominais de $\mathrm{pH}$ das soluções tampão adicionadas quando foram mantidas as razões volumétricas dessas soluções fixas, conforme procedimento experimental.

Os testes foram realizados com uma solução de DBSA III com concentração final de $0,09451 \mathrm{mmol} \mathrm{L}^{-1}$ na presença de excesso de bário. Percebeu-se que para valores de $\mathrm{pH}$ acima de 9,0, houve o desaparecimento do pico de absorção em $649 \mathrm{~nm}$, sendo constatado apenas o pico de absorção referente ao reagente DBSA III.

Os melhores sinais de absorvância foram observados em $\mathrm{pH}$ entre 2,0 e 3,0. Os testes seguintes foram realizados em $\mathrm{pH}$ 2,5, com tamponamento do meio com solução ácido cítrico/citrato de sódio 0,05 mol L ${ }^{-1}$, devido à melhor sensibilidade observada. Além disso, nesse pH existe a possibilidade de eliminação de interferentes metálicos e interferentes aniônicos como carbonatos e fosfatos. ${ }^{3}$

\section{Avaliação da concentração de bário para formação do complexo $\mathrm{Ba}^{2+}$-DBSA III}

No intuito de estudar a formação do complexo $\mathrm{Ba}^{2+}$-DBSA III para determinação indireta de sulfato, a concentração de $\mathrm{Ba}^{2+}$ foi avaliada na faixa entre 6,6 × $10^{-6}$ à $4,1 \times 10^{-4} \mathrm{~mol} \mathrm{~L}^{-1}$, mantendo-se a concentração do DBSA III em $0,0945 \mathrm{mmol} \mathrm{L}^{-1}$ no sistema reacional. Na Figura 3 é possível perceber um aumento linear dos sinais de absorvância medidos em 649 nm, referentes à formação do complexo, na medida em que íons $\mathrm{Ba}^{2+}$ foram adicionados até concentrações próximas de $0,066 \mathrm{mmol} \mathrm{L}^{-1}$. Para concentrações de bário variando de 0 a 0,066 mmol L $^{-1}\left(0\right.$ a $\left.9,1 \mathrm{mg} \mathrm{L}^{-1}\right)$, a equação analítica obtida que descreve a relação entre concentrações e sinais de absorvância foi: $A=12,65 \mathrm{C}+$ 0,009; ( $\mathrm{r}=0$ 0,9993), sendo A a absorvância e C a concentração de bário em $\mathrm{mg} \mathrm{L}^{-1}$.

A presença de bário livre no sistema reacional pode acarretar em precipitação de $\mathrm{BaSO}_{4}$ sem alteração na coloração da solução, consequentemente sem alteração no sinal analítico. Dessa forma, considerando que um pequeno excesso de DBSA III em relação ao $\mathrm{Ba}^{2+}$ é necessário para garantir que o cátion metálico permaneça na forma complexada $\mathrm{Ba}^{2+}$-DBSA III, manteve-se a concentração de bário em $0,066 \mathrm{mmol} \mathrm{L}^{-1}$ para os estudos posteriores.

\section{Avaliação de interferentes}

Espécies iônicas, potencialmente presentes em AEHC, foram

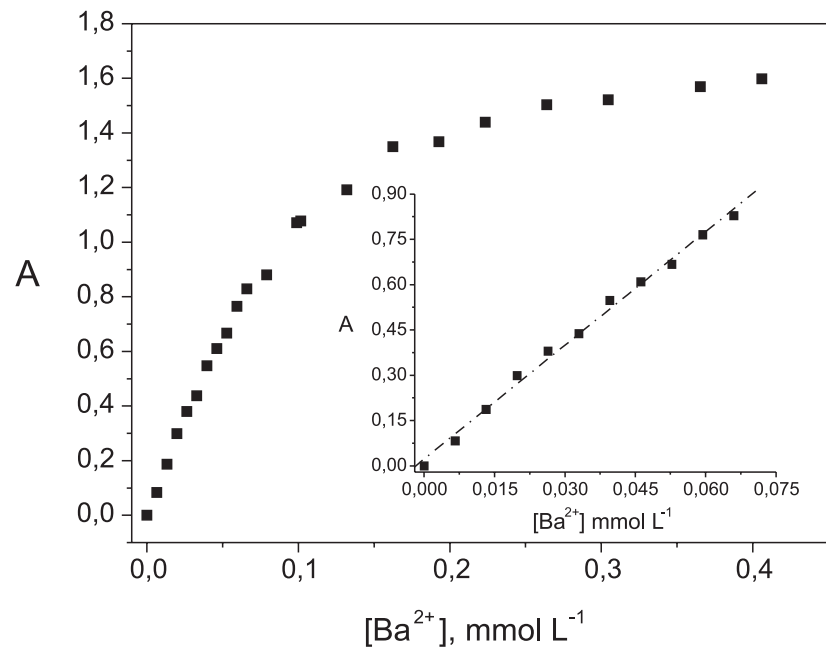

Figura 3. Avaliação da concentração de íons $B a^{2+}$ na formação do complexo com DBSA III. Condições: 0,09451 mmol L-1 de DBSA III tamponado em pH 2,5. Destaque para a faixa linear

avaliadas como possíveis interferentes na determinação espectrofotométrica indireta de sulfato por meio do complexo $\mathrm{Ba}^{2+}$-DBSA III. Neste estudo foi mantida constante a concentração de sulfato em $2,5 \mathrm{mg} \mathrm{L}^{-1}$ e admitiu-se que não houve interferência do íon quando a diferença do sinal analítico para a solução de referência de sulfato foi menor que $2 \%$. Verificou-se que $\mathrm{Mg}^{2+}, \mathrm{Pb}^{2+}, \mathrm{Zn}^{2+}, \mathrm{Fe}^{3+}$ e $\mathrm{Cu}^{2+}$ interferiram na determinação de sulfato em qualquer concentração. Entretanto, tais interferências foram contornadas pela adição de EDTA em concentração de $0,025 \mathrm{~mol} \mathrm{~L}^{-1}$. Os resultados obtidos são mostrados na Tabela 1. Na presença de EDTA, $\mathrm{Fe}^{3+}, \mathrm{Ca}^{2+}, \mathrm{Mg}^{2+}, \mathrm{Pb}^{2+}$, $\mathrm{Zn}^{2+}, \mathrm{Mn}^{2+}, \mathrm{CO}_{3}{ }^{2-}, \mathrm{Cl}^{-}, \mathrm{PO}_{4}{ }^{2-}, \mathrm{NO}_{3}{ }^{-}$foram tolerados em concentrações pelo menos quatro vezes maiores que a de $\mathrm{SO}_{4}{ }^{2-}$. $\mathrm{Para}_{\mathrm{Cu}^{2+}} \mathrm{e} \mathrm{Ni}^{2+}$, as concentrações toleradas foram duas vezes maiores que a de sulfato.

Tabela 1. Limite de tolerância de íons para determinação espectrofotométrica indireta de sulfato com DBSA III na presença de EDTA

\begin{tabular}{cc}
\hline Espécie Iônica & Concentração tolerada $\left(\mathrm{mg} \mathrm{L}^{-1}\right)^{*}$ \\
\hline $\mathrm{Fe}^{3+}$ & 10,0 \\
$\mathrm{Ca}^{2+}$ & 10,0 \\
$\mathrm{Cu}^{2+}$ & 5,0 \\
$\mathrm{Mg}^{2+}$ & 10,0 \\
$\mathrm{Ni}^{2+}$ & 5,0 \\
$\mathrm{~Pb}^{2+}$ & 10,0 \\
$\mathrm{Zn}^{2+}$ & 10,0 \\
$\mathrm{Mn}^{2+}$ & 10,0 \\
$\mathrm{CO}_{3}{ }^{2-}$ & 10,0 \\
$\mathrm{Cl}^{-}$ & 10,0 \\
$\mathrm{PO}_{4}{ }^{2-}$ & 10,0 \\
$\mathrm{NO}_{3}{ }^{-}$ & 10,0 \\
\hline
\end{tabular}

* Testes realizados na presença de $2,5 \mathrm{mg} \mathrm{L}^{-1}$ de sulfato.

Foi feita uma avaliação da influência do teor de etanol e verificou-se que para concentrações finais de etanol no sistema entre 20 e 60\% não havia diferenças significativas nos sinais de absorvância. Dessa forma, para as análises das amostras de AEC, as soluções de referência empregadas para obtenção da curva analítica tiveram os teores alcoólicos ajustados conforme os teores das amostras após diluição. Uma vez que se foram utilizados $5 \mathrm{~mL}$ de amostra de AEHC em um volume final de $10 \mathrm{~mL}$, para preparação das soluções de referência, adicionaram-se $5 \mathrm{~mL}$ de etanol hidratado. 


\section{Características analíticas do método e aplicação}

Empregando o procedimento proposto, realizou-se uma série de experimentos para obtenção da curva analítica, precisão e limite de detecção do método. Uma relação linear entre sinal de absorvância e concentração de sulfato foi observada quando a concentração do analito variou de 0,45 a $6,50 \mathrm{mg} \mathrm{L}^{-1}$, conforme a equação: A $=-0,151( \pm 0,002) \mathrm{C}+1,521( \pm 0,008)(\mathrm{R}=0,9991)$, sendo $\mathrm{A}$ a absorvância e $\mathrm{C}$ a concentração de sulfato em $\mathrm{mg} \mathrm{L}^{-1}$ (Figura 4). A repetibilidade do método proposto foi estimada em $2 \%$ com 15 medidas consecutivas de soluções contendo $2,5 \mathrm{mg} \mathrm{L}^{-1}$ de sulfato. O limite de detecção foi estimado em $0,14 \mathrm{mg} \mathrm{L}^{-1}$, utilizando a seguinte equação: $\mathrm{LD}=3 * s t d / m$, sendo $s t d$ o desvio padrão absoluto de 10 medidas do branco e $m$ o coeficiente angular da equação da curva de calibração. Na Tabela 2 são apresentadas características

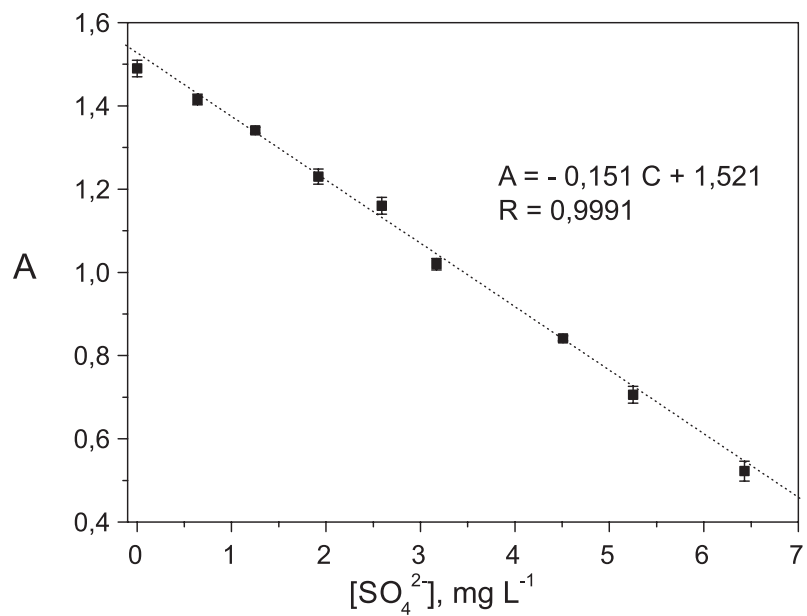

Figura 4. Curva analítica para determinação espectrofotométrica indireta de sulfato com DBSA III de métodos empregados para determinação espectrofotométrica indireta de sulfato em diferentes tipos de amostras. Conforme pode ser observado, o método proposto possui limite de detecção e precisão comparável com outros citados na literatura, ${ }^{3,9,18-28}$ além de apresentar uma faixa linear adequada para determinação de sulfato em amostras de AEC.

Para avaliar o desempenho do método, foram efetuados testes de recuperação por meio da adição de $2,58 \mathrm{mg} \mathrm{L}^{-1}$ de sulfato em amostras de AEHC coletadas em postos revendedores de combustíveis. Os resultados obtidos são apresentados na Tabela 3 como média de três determinações com os respectivos desvios padrão. Conforme pode ser observado, as recuperações obtidas variaram entre 91 a $112 \%$. Os resultados obtidos foram comparados com o método cromatográfico e são apresentados na Tabela 3. Com a aplicação de teste $t$ pareado, verificou-se que os valores encontrados não apresentaram diferença significativa para um nível de confiança de $95 \%$.

\section{CONCLUSÃO}

O método proposto apresenta-se como alternativa simples e rápida para determinação de sulfato em álcool etílico combustível. Os resultados obtidos ao aplicar o método apresentaram boa precisão com boa sensibilidade para determinação do analito e foram comparáveis com os obtidos aplicando-se a cromatografia de íons. Para aplicação do método, as amostra de álcool combustível não precisam ser submetidos a tratamentos prévios, evitando-se, dessa forma, procedimentos laboriosos com ácidos concentrados e aquecimento. O método proposto mostra-se adequado para ser aplicado em laboratórios de monitoração da qualidade de combustíveis como alternativa ao método oficial.

\section{AGRADECIMENTOS}

Os autores agradecem ao suporte financeiro do CNPq e CAPES.

Tabela 2. Métodos espectrofotométricos para a determinação indireta de sulfato em diferentes matrizes

\begin{tabular}{|c|c|c|c|c|c|}
\hline Reagente & Amostra & $\mathrm{LD}, \mathrm{mg} \mathrm{L}^{-1}$ & Faixa Linear, mg L ${ }^{-1}$ & Precisão, \% & Referência \\
\hline Dibromossulfonazo (III) & $\mathrm{AEC}$ & 0,14 & $0,45-6,50$ & 2 & Esse trabalho \\
\hline Borato de Th/Amarante & Águas de rio & - & até 400 & - & 18 \\
\hline Cloranilato de Bário & Águas e Óleos combustíveis & - & até 400 & 1 & 19 \\
\hline Azul de metiltimol & Águas de rio e de Poço & 0,5 & até 20 & 2 & 20 \\
\hline Dimetilsulfonazo (III) & Solos & 0,1 & até 5 & 2 & 9 \\
\hline Dimetilsulfonazo (III) & AEC & 0,27 & até 10 & 2,5 & 3 \\
\hline Cloranilato de Bário & Águas de Rio & 2,0 & até 40 & 2 & 21 \\
\hline Azul de metiltimol & Águas de Rio & - & até 6 & 4,1 & 22 \\
\hline Dimetilsulfonazo (III) & Águas de torneira, mineral e de rio & 0,03 & - & 1,2 & 23 \\
\hline Dimetilsulfonazo (III) & Águas naturais e residuais e biodiesel & 1,42 & até 15 & - & 24 \\
\hline Cloranilato de Bário & Efluentes & 0,039 & $10-1000$ & 0,26 & 25 \\
\hline Cloroanilato de Bário & Águas naturais & - & $5-10$ & 5 & 26 \\
\hline Cloroanilato de Bário & Águas naturais & 0,1 & $2,5-40$ & - & 27 \\
\hline 1,10-fenantrolina & Fertilizantes & _- & $0,1-0,5$ & 0,82 & 28 \\
\hline
\end{tabular}

Tabela 3. Determinação de sulfato $\left(\mathrm{mg} \mathrm{L}^{-1}\right)$ em álcool etílico hidratado combustível por meio de testes de adição e recuperação de 2,58 mg $\mathrm{L}^{-1}$ do analito aplicando-se os métodos proposto e comparativo $(n=3)$

\begin{tabular}{|c|c|c|c|c|c|}
\hline & Amostra A & Amostra B & Amostra C & Amostra D & Amostra E \\
\hline Com adição de sulfato & $5,45 \pm 0,05$ & $5,58 \pm 0,06$ & $3,93 \pm 0,05$ & $5,12 \pm 0,04$ & $4,62 \pm 0,03$ \\
\hline Sem adição de sulfato & $2,67 \pm 0,03$ & $3,28 \pm 0,05$ & $1,21 \pm 0,04$ & $2,71 \pm 0,02$ & $1,87 \pm 0,05$ \\
\hline Recuperação, \% & 107 & 91 & 112 & 94 & 109 \\
\hline Método Comparativo ${ }^{13}$ & 2,75 & 3,13 & 1,28 & 2,91 & 1,88 \\
\hline
\end{tabular}




\section{REFERÊNCIAS}

1. Teixeira, L. S. G.; Leão, E. S.; Dantas, A. F.; Pinheiro, H. L. C.; Costa, A. C. S.; de Andrade, J. B.; Talanta 2004, 64, 711.

2. de Lima, T. A. F.; Ferreira, H. B. P.; Barbeira, P. J. S.; Br. J. Anal. Chem. 2011, 6, 296.

3. Oliveira F. S.; Korn M.; Talanta 2006, 68, 992.

4. Teixeira, L. S. G.; Chaves, T. J.; Guimarães, P. R. B.; Pontes, L. A. M.; Teixeira, J. S. R.; Anal. Chim. Acta 2009, 640, 29.

5. Teixeira, L. S. G.; Brasileiro, J. F.; Borges Jr, M. M.; Cordeiro, P. W. L., Rocha, S. A. N.; Costa, A. C. S.; Quim. Nova 2006, 29, 741.

6. Prada, S. M.; Guekezian, M.; Suárez-Iha, M. E. V.; Quim. Nova 1998, $21,249$.

7. http://www.anp.gov.br, acessada em Agosto 2012.

8. Pereira, E. A.; Tavares, M. F. M.; Arnaldo, A. S.; Cardoso, A. A.; Quim. Nova 2006, 29, 66.

9. Meneses, S. R. P.; Maniasso, N.; Zagatto E. A. G.; Talanta 2005, 65, 1313.

10. Marques, G. S.; Monteiro, R. P. M. M.; Leão, W. F.; Lyra, M. A. M.; Peixoto, M. S.; Rolim-Neto, P. J.; Xavier, H. S.; Soares, L. A. L.; Quim. Nova 2012, 35, 517.

11. Rocha, F. R. P.; Teixeira, L. S. G.; Quim. Nova 2004, 27, 807.

12. Kemp, P. J.; Williams, M. B.; Anal. Chem. 1973, 45, 124.

13. ABNT - Associação Brasileira de Normas Técnicas, Etanol combustível - Determinação da concentração de cloreto e sulfato - Método da cromatografia de íons, NBR 10894, Rio de Janeiro, 2012.
14. Budesinsky, B.; Varzalova, D.; Chem. Anal. 1966, 55, 110.

15. http://www.guidechem.com/reference/dic-132409.html, acessada em Outubro 2012.

16. Rohwer, H.; Hosten, E.; Anal. Chim. Acta 1997, 339, 271.

17. Rohwer, H.; Hosten, E.; Anal. Chim. Acta 1997, 345, 227.

18. Lambert, J. L.; Yasuda, S. K.; Grotheer, M. P.; Anal. Chem. 1955, 27, 800.

19. Bertolacini, R. J.; Barney, J. E.; Anal. Chim. 1957, 29, 281.

20. Maniasso, N.; Jacintho, A. O.; Giné, M. F.; Quim. Nova 1995, $18,147$.

21. Crnkovic, P. M.; Jacintho, A. O.; Quim. Nova 2002, 25, 254.

22. Madsen, B. C.; Murphy, R. J. Anal. Chem. 1981, 53, 1924.

23. Burakham, R.; Higuchi, K.; Oshimac, M.; Grudpan, K.; Motomizu, S.; Talanta 2004, 64, 1147.

24. del Río, V.; Larrechi, M. S.; Callao, M. P.; Anal. Chim. Acta 2010, 676, 28.

25. Roy, A.; Das, B. K.; Bhattacharya, J.; Mine Water Environ. 2011, 30, 169.

26. Ueno, K.; Sagara, F.; Higashi, K.; Yakata, K.; Yoshida, I.; Ishii, D.; Anal. Chim. Acta 1992, 261, 241.

27. Bonifácio, V. G.; Salami, F. H.; Marcolino-Junior, L. H.; Fatibello-Filho, O.; Anal. Lett. 2011, 44, 298.

28. Yasmin, F.; Anwar, J.; Zaman, W. U.; J. Chem. Soc. Pak. 2000, 22, 98. 